\title{
Análise Pluridisciplinar das Situações de Trabalho: para além da avaliação de desempenho dos trabalhadores do setor de saúde pública no estado de Minas Gerais Multidisciplinary Analysis of Work Situations: beyond the performance evaluation of workers from the public health sector in the state of Minas Gerais
}

\author{
João César de Freitas Fonseca \\ Psicólogo. Doutor em Educação. Professor Adjunto da Universidade \\ Federal de São João Del Rei. Professor colaborador da Fundação \\ João Pinheiro. \\ Endereço: Rua Madressilva 543, Pompeia, CEP 30280-180, Belo \\ Horizonte, MG, Brasil. \\ E-mail: joaocesar.fonseca®yahoo.com.br

\section{Carlos Eduardo Carrusca Vieira} \\ Psicólogo. Doutorando em Psicologia pela UFMG. Professor Assis- \\ tente da PUC Minas. Subcoordenador do Laboratório de Psicologia \\ Organizacional e do Trabalho (LaPOT). \\ Endereço: Rua Ituverava, 268, Apto 201, Bairro Renascença, CEP \\ 30130-590, Belo Horizonte, MG, Brasil. \\ E-mail: carloseduardo_carrusca®yahoo.com.br
}

\section{Resumo}

O presente ensaio apresenta considerações críticas sobre o processo de Avaliação de Desempenho Individual (ADI) ao qual estão atualmente submetidos os servidores do setor de saúde do estado de Minas Gerais, chamando a atenção para o caráter de alta complexidade desse setor e recomendando a adoção de metodologias mais abrangentes, como a Análise Pluridisciplinar das Situações de Trabalho (APST), proposta pelo filósofo francês Yves Schwartz. Este texto resulta da experiência dos autores na formação de trabalhadores e na gestão de serviços de saúde na área pública, não constituindo relato de pesquisa stricto sensu, nem demonstração de dados conclusivos de pesquisa empírica, mas antes um ensaio/ convite à reflexão e ao diálogo sobre os riscos de cristalização de uma visão excessivamente funcionalista dos processos de gestão de pessoas no setor público da saúde.

Palavras-chave: Psicologia do trabalho; Gestão de Saúde Pública; Avaliação de desempenho. 


\section{Abstract}

This essay presents critical considerations about the process of Evaluation of Individual Performance (EIP) to which the servers of the health sector of the state of Minas Gerais are currently subject, drawing attention to the character of high complexity of this sector and recommending the adoption of more comprehensive methodologies, like the Multidisciplinary Analysis of Work Situations (MAWS), proposed by Yves Schwartz. This text results from our experience in the regency of courses in the area of Human Resources for healthcare workers, and we would like to emphasize that this is not a scientific article that presents data from conclusive empirical research, but a call for reflection and dialogue on the risks of crystallization of an excessively functionalist view of the procedures for managing people in the public health sector.

Keywords: Psychology of Work; Public Health Management; Performance Evaluation.

\section{Introdução}

Nos mais variados campos de estudo e nas diversas áreas do conhecimento, muito se tem discutido em torno do papel do Estado frente à sociedade e às exigências que parecem suceder-se em ritmo crescente. Educação, segurança, saúde e transporte são muitas vezes entendidos como "temas-chave", o que leva pesquisadores e institutos de investigação à reflexão frente aos desafios que se apresentam para trabalhadores, gestores e organizações dessas áreas.

Muitas dessas análises são balizadas pelo alinhamento ideológico e político de seus propositores, os quais, em linhas gerais, irão defender ou criticar as propostas de reforma do setor público. As propostas favoráveis estão em grande parte alinhadas às reformas de cunho liberalizantes adotadas em vários países, de modo mais agudo a partir das décadas de 1980 e 1990 (Keinert, 1994; Paes de Paula, 2003).

Conforme Abrucio (1997), a crise do Estado poderia ser sentida em três de suas dimensões: econômica, social e administrativa. Na primeira, o modelo keynesiano de Estado, que se caracterizava pela intervenção ativa na economia, através da produção de bens, serviços e infraestrutura, mostrou-se esgotado em virtude da contínua diminuição do crescimento econômico dos países e da crise de financiamento do setor público. Este último também gerou reflexos negativos na dimensão social, que se caracterizava pela adoção do chamando Welfare State - Modelo de Estado, em que o governo assume a responsabilidade pela implementação de uma quantidade considerável de políticas públicas em diversas áreas sociais (habitação, educação, saúde etc.) - que, por sua vez, provocou uma crise fiscal em diversos países pela sobrecarga de funções. Na dimensão administrativa, a crise caracterizou-se pela falência do modelo burocrático weberiano que, embora tenha procurado extirpar da cultura administrativa governamental práticas de clientelismo, nepotismo etc. através da adoção de princípios como a impessoalidade e a meritocracia, mostrou-se pouco eficaz na satisfação das demandas por serviços públicos e ineficiente na aplicação de recursos públicos.

Assim sendo, tornava-se necessário repensar o papel do Estado em cada uma daquelas três dimensões. A chamada Reforma do Estado foi caracteriza- 
da por um conjunto de reformas de natureza variada (fiscal, previdenciária, administrativa, ideológica, dentre outras) pelo qual passou a grande maioria dos países capitalistas a partir da década de 1980, na tentativa de solucionar cada uma das múltiplas facetas da crise do Estado.

A incerteza quanto à possível perenidade dos chamados ajustes estruturais - considerando inclusive a insuficiência do ajuste fiscal e das reformas orientadas para o mercado em promover a retomada do crescimento - implicou na manutenção do tema Reforma do Estado com destaque nas agendas governamentais (Pereira, 2001).

É importante observar que, no caso do acolhimento por parte dos gestores públicos da lógica de redução do Estado como prerrogativa de incremento qualitativo, seria possível identificar pressupostos de dois grandes grupos argumentativos: um de natureza financeira, outro de natureza administrativa. Nesse sentido, podemos citar Nogueira e Santana (200o, p. 4):

No aspecto financeiro, os reformistas [do Estado] partiam do diagnóstico de que a máquina do Estado estava inchada de servidores, os quais custavam muito e faziam pouco. No aspecto administrativo, partiam do preceito segundo o qual o estilo burocrático de administração pública, que era favorecido pela cultura peculiar aos seus servidores, deveria ser substituído por um estilo gerencial similar ao que é adotado nas empresas privadas.

Essa representação, de um Estado que adotasse estratégias reproduzidas a partir das práticas de gestão típicas do setor privado, não se mostrou capaz de sustentação por período mais dilatado. Prova disso é o curto período de existência e controversa atuação do Ministério de Administração e Reforma do Estado (Mare), no âmbito da Administração Pública Federal.
Com características específicas, tais movimentos atingiram também os níveis das administrações públicas estaduais e municipais, sendo possível observar em todas elas, de forma geral, uma carência enorme de pessoal qualificado e, ao mesmo tempo, um recrudescimento das pressões da sociedade pela oferta de melhores serviços.

Alinhado a essa perspectiva, o governo do estado de Minas Gerais propôs, a partir da gestão Aécio Neves, o aprimoramento da administração pública estadual através de diversos programas e projetos. A pretensão de otimizar a alocação de recursos públicos envolvendo um controle por resultados a partir de indicadores quantitativos e ou qualitativos mensuráveis seria executada através do programa Gestão Estratégica de Recursos e Ações do Estado - Geraes, composto por 30 Projetos Estruturadores, cada qual com um gerente responsável por sua execução. Integrado a esse contexto temos o chamado Choque de Gestão.

Vilhena (2006) ${ }^{1}$ afirma que "o choque de gestão é um conjunto integrado de políticas de gestão pública orientado para o desenvolvimento", que se traduz na prática pela implantação de uma série de medidas administrativas, majoritariamente próximas de modelos e práticas originários do setor privado.

Uma das medidas integrantes do Choque de Gestão é a implantação da Avaliação de Desempenho Individual (ADI) dos servidores públicos estaduais, mediante parâmetros previamente definidos em lei específica ${ }^{2}$ e com repercussões sobre o sistema de remuneração e sobre a própria permanência dos servidores no quadro de funcionários.

Vários estudos (Fonseca e Oliveira, 2005; Pontes, 2002; Abbad, 1991; ENAP, 200o) apontam as limitações dos programas de avaliação de desempenho e lembram a importância de sua compreensão como um processo, principalmente levando-se em consideração o alto grau de insatisfação que muitas

\footnotetext{
1 A autora ocupa a função de secretária-adjunta de planejamento e gestão do estado de Minas Gerais e gerente do projeto estruturador choque de gestão: pessoas, qualidade e inovação.

2 Dentre outros, ver: Minas Gerais. Lei complementar n. 71, 30/7/2003. Institui a avaliação periódica de desempenho individual, disciplina a perda de cargo público e de função pública por insuficiência de desempenho do servidor público estável e do detentor de função pública na Administração Pública direta, autárquica e fundacional do Poder Executivo e dá outras providências. Ver também: Minas Gerais. Lei complementar n. 72, 30/7/2003. Institui o Afastamento Voluntário Incentivado - AVI - no âmbito da Administração Pública direta e fundacional do Poder Executivo e dá outras providências.
} 
vezes é decorrente da adoção desse instrumento, em particular na administração pública.

Do ponto de vista crítico adotado pela Psicologia do Trabalho, a elaboração de um instrumento quantitativo de avaliação do desempenho e o processo de sua implementação, mediado pelos gestores, caracterizam importantes objetos de análise, uma vez considerados seus possíveis desdobramentos para as práticas de gestão e para os indivíduos avaliados.

Isso porque, para aqueles que não renunciam à compreensão crítica das relações de trabalho e seus desdobramentos sobre as condições vividas pelos trabalhadores, é sabido que a formulação de qualquer instrumento que tenha como pretensão traduzir para dados quantitativos determinados aspectos de uma expressão parcial da realidade - no caso o "desempenho" - pressupõe escolhas, feitas de forma explícita ou tácita, dos fatores que podem potencialmente se constituir como indicadores. A escolha e a conversão dos "fatores determinantes do desempenho" em "perguntas" e "possibilidades de resposta", indicativas de certa realidade, são aspectos passíveis de interrogação, exatamente por serem indissociáveis da questão de valores. Em pesquisa recentemente publicada, Porto e Tamayo (2007, p. 69) insistem quanto à "necessidade de integração dos modelos de valores gerais com os modelos de valores laborais, contribuindo para a compreensão do sistema de valores dos indivíduos".

Da mesma forma, a formulação, implementação e análise dos resultados fornecidos pela avaliação de desempenho são etapas precedidas e parcialmente predeterminadas pela escolha dos componentes identificados como determinantes do desempenho. A escolha desse conjunto de variáveis condiciona, nesta perspectiva, o quanto dessa "realidade" será apreendida e/ou subtraída pelo instrumento, afetando diretamente seus resultados.

Essa pressuposição justifica o regresso à questão: de quais fatores depende o desempenho? Aparentemente simples, essa indagação nos conduz a interrogações mais complexas, justificadas pelo propósito de se entender como o "desempenho" pode ser avaliado/mensurado. Tratando-se do desempenho, não há caminho simples para sua avaliação, que não faça o percurso entre a objetividade e a subjetividade, encarnados na atividade de trabalho. Apesar do que se tem preconizado, as contribuições de um determinado indivíduo não são levadas à organização do trabalho sem obstáculos e restrições. 0 próprio desempenho no trabalho não é determinado apenas pela "boa vontade" do indivíduo como às vezes se idealiza. Há constrangimentos de ordem técnica, organizacional e material que cerceiam o desenvolvimento de uma atividade de trabalho e, por conseguinte, limitam e/ou precarizam a consecução de certos objetivos organizacionais, principalmente quando consideradas as dimensões subjetivas (Dejours, 2004). Como tais constrangimentos têm sido considerados nas avaliações de desempenho?

Em nosso entendimento, na avaliação de desempenho individual veem-se negligenciadas certas interferências, efetivamente reais, das condições e da organização de trabalho, motivo pelo qual se pode questionar sua capacidade de representar, efetivamente, a variável "desempenho".

Quais os fatores condicionam o desempenho, quais deles têm sido considerados em uma proposta de avaliação e quais as repercussões dessa metodologia/escolha para análise do desempenho dos servidores?

\section{Saúde: um setor como os outros?}

Tais considerações, válidas para qualquer tipo de organização, ganham ainda mais força quando nos referimos às organizações públicas da área da saúde, a qual, nesse sentido, mostra-se como ponto crítico, necessitando urgentemente de proposições mais consistentes em termos de fundamentação teórica e metodológica, sob pena de agravamento dos cenários já tão reconhecidamente desgastados.

No Brasil, é possível reconhecer que desde a promulgação das Leis Orgânicas de Saúde (Leis n. 8.88o e n. 8.142/9o), a questão da força de trabalho - e de sua gestão - no Sistema Único de Saúde (SUS) tem sido apontada como um dos elementos de maior complexidade, percebida até mesmo como um dos nós críticos da sua implementação.

Trata-se, na verdade, de um paradigma recorrente na implementação de políticas públicas na sociedade brasileira: as perspectivas de modernização, a premência de atendimento, as pressões por realizações 
em mandatos políticos não necessariamente sequenciais usualmente conduzem a uma subsunção da preocupação com os trabalhadores do setor público, com os sujeitos que efetivamente sustentarão tais políticas. Subestimar a importância do reconhecimento das dimensões subjetivas sobre a realização de escolhas e tomada de decisões administrativas, mais do que um equívoco político, pode significar a derrocada da própria proposta de aprimoramento de serviços, ainda que a longo prazo.

Como consequência, é possível observar o recrudescimento, por parte de gestores e organizações de saúdes públicas e privadas, da adoção de técnicas e instrumentos de aferição de resultados, que possam saciar a expectativa de uma prestação de serviços mais eficaz, eficiente e efetiva. No que diz respeito ao setor público, essa ânsia de gestão pode ser encontrada nos diferentes níveis da administração pública e parece ser potencializada na medida em que tais organizações se defrontam com a lógica das certificações, já experimentadas por outros segmentos do setor produtivo há algumas décadas.

Torna-se inevitável, a nosso ver, problematizar a compreensão reducionista - à medida que excessivamente funcionalista - daqueles elementos que efetivamente constituem a atividade desenvolvida pelos servidores públicos na área da saúde. Quando se faz opção pela prevalência desse modelo de execução de políticas públicas, excessivamente centralizado nos produtos finais (resultados) e pouco atento aos processos (meios), descarta-se a indispensável escuta dos trabalhadores e relega-se a um segundo plano a adoção de metodologias que permitam a emersão da realidade das situações de trabalho dos profissionais cujas vidas "fazem acontecer" outras vidas.

A adoção de mecanismos como a Análise Pluridisciplinar das Situações de Trabalho, recorrendo às noções da Psicologia do Trabalho, da Ergonomia, da Ergologia, pode significar expressivos avanços para a concretização de relações de trabalho mais justas, saudáveis e certamente mais coerentes com os princípios de universalidade e integralidade (para citar apenas dois) que norteiam (ou pelo menos, deveriam) o SUS. Ou será que o texto da lei não se refere às questões relacionadas à saúde física e mental dos trabalhadores do próprio setor de saúde?

\section{Possíveis contribuições}

A linha central de argumentação nesse texto é a defesa da noção de atividade, tal como proposto pelo filósofo francês Yves Schwartz, que propõe a Análise Pluridisciplinar das Situações de Trabalho (APST). Interessado basicamente no processo de produção e reformulação dos saberes ligados ao trabalho humano, Schwartz (1996, 2000, 2004a, 2004b) tem chamado a atenção de estudiosos da Educação, Engenharia, Psicologia, Linguística e outras áreas para a importância de aprofundar os estudos em torno da dinâmica entre trabalho prescrito e trabalho real.

Ora, parece-nos que a ADI caminha exatamente sobre essa região, bastante nebulosa, uma vez que os critérios de avaliação de desempenho - como já o dissemos - serão sempre passíveis de discussão e análise.

Em um de seus textos, Schwartz (2004a, p. 50) utiliza inclusive a figura do hospital para ilustrar sua argumentação, o que parece ser bastante oportuno reproduzir aqui:

No hospital, a eficácia toma sentido parcialmente diferente para a equipe de direção, os médicos, os enfermeiros e atendentes, ainda que 'a volta à saúde' seja o objetivo final sem dimensão ao qual todos se referem em graus diversos e que mantém um mínimo inteiramente real de consenso.

Argumentando sobre o Tempo Médio de Permanência - um dos parâmetros de avaliação dos serviços prestados pela instituição -, Schwartz discute exatamente a relação crítica entre os protagonistas/ trabalhadores e os indicadores derivados dos objetivos de eficácia dimensionados pela direção da organização. Essa questão, tão recorrente no discurso dos técnicos e gestores das áreas de recursos humanos das organizações de saúde pública, poderia ser melhor enfrentada com os recursos da APST.

O sociólogo Gilbert de Tersac, da Universidade de Toulouse Le Mirail, explanando sobre a abordagem ergonômica do trabalho, recomenda:

"Uma atenção particular deveria ser dada às vivências do trabalho e aos sistemas de valor que 'qualificam oficialmente' [...] certas tarefas como penosas e outras como de valor. Compreender as novas formas de trabalho não seria também com- 
preender as modalidades de gestão dos trabalhadores e da estruturação dos empregos, bem como a articulação entre as representações e o modo de vida? Em suma, substituir uma visão normativa por uma análise de práticas plurais, que fazem do trabalho de significados múltiplos, resultando em formas de organização singulares [...] a noção de situação de trabalho é complementada pela análise das trajetórias e biografias individuais ou coletivas. Enfim, a noção de trabalho é cada vez menos considerada como um dado, e cada vez mais como uma construção social, um produto da ação individual e coletiva”. (Tersac e col., 2004, p. 84) [grifo nosso]

Tendo em vista as limitações desse ensaio, optamos por tomar as considerações desse autor como ilustrativas do nosso argumento, na expectativa de encontrar aí um piso teórico consistente o bastante para sustentar a ideia de que a real investigação sobre o trabalho nas organizações de saúde pública demanda ações que ultrapassem as possibilidades da ADI. Ao defender a ideia do trabalho como configurações singulares - e portanto demandante de olhares múltiplos. Tersac (op. cit.) sugere:

\section{Um olhar sobre a diversidade dos mundos do tra- balho}

Essa certamente é uma das recomendações que encontra eco imediato nas instituições públicas de saúde, onde convivem servidores efetivos (contratados mediante concurso público), terceirizados (em número crescente derivado das políticas de esvaziamento da força de trabalho do setor público), estagiários, voluntários, consultores. Lembrando ainda que, dentre os servidores efetivos, é possível encontrar às vezes servidores públicos federais e municipais disponibilizados ou em exercício em instituições do governo estadual, tornando certamente ainda mais complexa a tarefa de identificar valor e negociar resultados, uma vez que a interdependência marca cada vez mais os processos de trabalho no campo da saúde.

\section{Um olhar sobre as trajetórias e as biografias pessoais}

A pretensão de que instrumentos como a ADI ou quaisquer outros derivados da lógica da racionalidade administrativa deem conta da diversidade que constitui a força de trabalho no setor de saúde seria, no mínimo, superestimar tal ferramenta. Questões como diferenças de gênero, raça, gerações e classe afetam a efetividade desses instrumentos que não possuem sensibilidade suficiente para captar as dimensões políticas inerentes às relações de poder vividas nas organizações.

Podemos utilizar a questão da diferença de gerações, principalmente quando recordamos a importância da figura do gestor na ADI e confrontamos com as proposições do pesquisador Thiry-Cherques (2004, p. 620), quando afirma:

"A administração pública se encontra envelhecida, em parte devido às características da própria função pública [...], em parte devido às dificuldades orçamentárias com que se defronta e em parte devido à desqualificação real e percebida do serviço público, que afasta os candidatos mais promissores aos cargos executivos".

Segundo esse mesmo autor "as teses sobre o mundo social e sobre o destino da vida particular, expressas pelos jovens executivos, são de tal forma distantes das dos demais grupos etários que não há propriamente conflito entre elas, mas desinteresse e indiferença”.

\section{Um olhar sobre o trabalho como uma ação coletiva dentro de um contexto estruturado}

A defesa que Tersac e colaboradores (op. cit.) fazem do trabalho como uma realidade a ser construída é bem convergente com a situação relatada a nós por gestores das áreas de recursos humanos das organizações públicas de saúde do estado de Minas Gerais. Todo o esforço que vem sendo feito na capacitação desses profissionais e técnicos pode estar ameaçado de não lograr o êxito esperado - pela organização, por eles próprios e pelos servidores - se a linha de formação mantiver-se restrita à noção de que esse técnico/gestor conseguirá, à força de argumentos técnicos e com o apoio da legislação, efetuar a tão desejada mudança na cultura organizacional.

Tais estudos podem ajudar a recuperar dimensões até agora inatingíveis para os modelos de Avaliação de Desempenho, por mais modernos e sofisticados que estes possam ser. Isso porque uma das maiores críticas que se fazem à Avaliação de Desempenho é a de que ela sempre carrega uma forte carga de sub- 
jetividade, tanto por parte dos avaliadores quanto dos indivíduos avaliados. Nossa perspectiva é a de reconhecer e interrogar tal dimensão subjetiva, ao invés de simplesmente ignorá-la.

Processos institucionais marcados historicamente por um enorme potencial de conflito, vinculados direta ou indiretamente à avaliação de desempenho, poderiam se beneficiar significativamente a partir da inclusão das falas, dos anseios, dos discursos de trabalhadores e gestores, até então reiteradamente mantidos no nível dos registros formais, efetuados em campos específicos dos formulários e nem sempre relevantes quando da aferição dos instrumentos e programas.

A título de exemplo, podemos pensar na situação da readaptação funcional. Os servidores nessa situação, ainda que tenham seus direitos preservados no que diz respeito à dimensão jurídica, vivem situações de conflito intenso, que não se traduz com muita clareza na avaliação de desempenho. São avaliados pelos instrumentos de quantificação de desempenho com base nas expectativas do que deveriam estar fazendo, caso estivessem no posto inicial, ou com base nas tarefas designadas/incluídas pela readaptação funcional? Trata-se de uma situação na qual não há clareza sobre os parâmetros de avaliação. 0 exemplo evidencia, com nitidez, que, ainda que mantida a legalidade, certamente encontra-se ameaçada a legitimidade do processo do instrumento de avaliação, se considerados os constrangimentos impostos pela variabilidade das situações reais de trabalho. Evitar reconhecer a dimensão do trabalho real significa desprezar fatores que condicionam o desempenho.

\section{Considerações Finais}

Assim, se por um lado o reconhecimento das condições reais de realização do trabalho constitui um desafio, implica uma mudança de olhar, por outro enseja a criação de métodos capazes de capturar as necessidades organizacionais e individuais, de forma mais próxima.

Gestores têm-se perguntado sobre como a avaliação de desempenho pode se constituir como fee- dback do desempenho individual e organizacional e, ainda, caracterizar-se como princípio de mudanças comportamentais.

Alguns depoimentos de servidores do campo da saúde pública indicam que certos elementos presentes no processo de implementação da avaliação de desempenho têm prejudicado as análises e distanciado o diagnóstico organizacional da realidade efetiva.

A explanação clara sobre o processo de avaliação e sobre o próprio instrumento parece se configurar como um primeiro fator que, embora realizado pelas instâncias responsáveis, tem limitações significativas, as quais se reapresentam cotidianamente para trabalhadores e gestores. Muitas vezes, o desconhecimento e a resistência a esse processo manifestam-se em fantasias diversas por parte dos servidores, prejudicando em alguns casos a relação com o trabalho. 0 processo é marcado por insatisfações, ansiedades e receios quando não se esclarecem os objetivos, o funcionamento e as possíveis ações derivadas dos resultados das avaliações de desempenho. O risco de se tornar "mais um papel a ser preenchido" é iminente nesses casos.

\section{Referências}

\section{ABBAD, G. S. Sistemas de avaliação de} desempenho: opinião de avaliadores e avaliados. 1991. Dissertação-Instituto de Psicologia da Universidade de Brasília, Brasília, DF, 1991.

ABRUCIO, F. L. O impacto do modelo gerencial na administração pública: um breve estudo sobre a experiência internacional recente. Brasília, DF: ENAP, 1997.

DEJOURS, C. Addendum: da psicopatologia à psicodinâmica do trabalho. In: LANCMAN, S.; SZNELWAR, L. (Org.). Christophe Dejours: da psicopatologia à psicodinâmica do trabalho. Rio de Janeiro: Fiocruz, 2004. p. 47-104.

ENAP - ESCOLA NACIONAL DE ADMINISTRAÇÃO PÚBLICA. Experiências de avaliação de desempenho na Administração Pública Federal. Brasília, DF, 2000. 
FONSECA, J. C. de F.; OLIVEIRA, R. O. F. Avaliação de desempenho individual como instrumento de aperfeiçoamento da gestão pública: estudo de caso no governo de Minas Gerais. In: CONGRESSO DO CLAD, 10., 2005, Santiago. Anais do X Congresso Latino Americano de Administração Pública.

Santiago: CLAD, 2005. p. 1-33.

NOGUEIRA, R. P.; SANTANA, J. P. Gestão de recursos humanos e reformas do setor público: tendências e pressupostos de uma nova abordagem. Belo Horizonte: [s.n.], 2000. Disponível em: <http://www.opas.org.br/rh/admin/ documentos/ACF22.pdf >. Acesso em: 15 jan. 2008.

KEINERT, T. M. M. Os paradigmas da administração pública no Brasil (190o-92). Revista de Administração de Empresas, Rio de Janeiro, v. 43, n. 3, p. 41-48, 1994.

PAES DE PAULA, A. P. Entre a administração e a política: os desafios da gestão pública democrática. 2003. Tese (Doutorado em Ciências Sociais)-Instituto de Filosofia e Ciências Humanas da Universidade Estadual de Campinas, Campinas, 2003.

PEREIRA, L. C. B. Administração pública gerencial: estratégia e estrutura para um novo Estado. Brasília, DF: ENAP, 2001.

PONTES, B. R. Avaliação de desempenho: nova abordagem. São Paulo: LTr, 2002.

PORTO, J.; TAMAYO, A. Estrutura dos valores pessoais: a relação entre valores gerais e laborais. Psicologia: Teoria e Pesquisa. Brasília, DF, v. 23 n. 1, p. 63-70, 2007.
SCHWARTZ, Y. Os ingredientes da competência: um exercício necessário para uma questão insolúvel. Educação e Sociedade. Campinas, v. 19, n. 65, p. 101-140, 1996.

SCHWARTZ, Y. Trabalho e uso de si. Pro-Posições. Campinas, v.1, n. 5, p. 34-50, 2000.

SCHWARTZ, Y. Circulações, dramáticas, eficácias da atividade industriosa. Trabalho, Educação e Saúde, Rio de Janeiro, v. 2, n. 1, p. 33-55. 2004 a.

SCHWARTZ, Y. Ergonomia, filosofia e extraterritorialidade. In: DANIELLOU, F. (Org.). A ergonomia em busca de seus princípios: debates epistemológicos. São Paulo: Edgard Blücher, 2004b. p. 141-18o.

TERSAC, G. et al. O trabalho e a abordagem ergonômica. In: DANIELLOU, F. (Org.). A ergonomia em busca de seus princípios: debates epistemológicos São Paulo: Edgard Blücher, 2004. p. 8o-104.

THIRY-CHERQUES, H. R. O conformismo impaciente: uma interpretação do quadro de referência ética dos jovens executivos nas organizações brasileiras. Revista de Administração Pública, Rio de Janeiro, v. 38, n. 4, p. 613-642, 2004.

VILHENA, R. (Org.). O choque de gestão em Minas Gerais: políticas de gestão pública para o desenvolvimento. Belo Horizonte: UFMG, 2006.

Recebido em: 01/02/2010

Reapresentado em: 27/09/2010

Aprovado em: 29/10/2010 